\title{
A Simple Biological Treatment for a Slaughterhouse Wastewater
}

\author{
Rafaela Paes de Souza Barbosa, Maria Magdalena Ribas Döll* and Ana Cláudia Barana \\ Universidade Estadual de Ponta Grossa, Brazil \\ *Corresponding author: Maria Magdalena Ribas Döll, Universidade Estadual de Ponta Grossa, Brazil
}

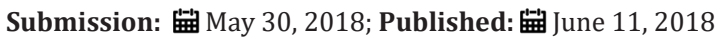

\begin{abstract}
Wastewater coming from slaughterhouses by-products contains high amounts of nitrogen, phosphorus, organic matter, salts, and so on. The effluent comes from the water used to wash the animals, scalding, washing the floor and the machines, cleaning of equipment, etc. Before discharging the effluent in the water body, the effluent needs to be treated. To remove the large amount of organic matter and nutrients this study proposed the use of a combined system composed by three biological reactors: anaerobic, aerobic and anoxic. The best removal efficiencies were $90 \%$ for COD and 50\% for $\mathrm{NH}_{4}+-\mathrm{N}$, what decreases large pollutant potential.
\end{abstract}

Keywords: Slaughterhouse; Biological treatment; Nutrients removal; Organic matter removal

Abbreviation: PVC: Polyvinyl Chloride; HRT: Hydraulic Retention Time; TP: Total Phosphorus; TKN: Total Kjeldahl Nitrogen; TS: Total Solids; TSS: Total Suspended Solids; VSS: Volatile Suspended Solids

\section{Introduction}

The pollution of water has increased due the improper discharge of effluents. Therefore, the search for adequate and efficient treatments for effluents has become crucial for the society development The pollution of water has increased due the improper discharge of effluents. Therefore, the search for adequate and efficient treatments for effluents has become crucial for the society development [2] . Slaughterhouse wastewater is composed by high amount of organic matter, nitrogen, phosphate, oil, grease and suspended solids [3]. This effluents with high concentration of nutrients need to go through treatment before being discharged into the water body, because nitrogen and phosphorus in excess causes eutrophication. Anaerobic processes are commonly used as a wastewater treatment to remove organic matter, but they are not efficient to remove nutrients. For this reason, to remove nitrogen and phosphorus is essential that the system also have an aerobic and anoxic reactor. This present investigation aimed to evaluate the combined system by an anaerobic, aerobic and anoxic reactors removal efficiency of organic matter, ammonium nitrogen and total phosphorus.

\section{Materials and Methods}

\section{Combined system}

The upflow anaerobic reactor was made of polyvinyl chloride (PVC) tube with height of $0.31 \mathrm{~m}$ (headspace of $0.06 \mathrm{~m}$ ) and diameter of $0.10 \mathrm{~m}$. Filled with polyurethane foam cubes $\left(10^{-6} \mathrm{~m}^{3}\right)$ and $30 \%$ $(v / v)$ of anaerobic granular sludge. The volume of biogas produced by the anaerobic reactor was quantified by water displacement. The total and useful volumes were $2.6 \mathrm{~L}$ and $1.4 \mathrm{~L}$, respectively. The aerobic reactor had a total height of $0.56 \mathrm{~m}$ and diameter of $0.10 \mathrm{~m}$ and a biomass decanter $0.15 \mathrm{~m}$ from the bottom (height of $0.05 \mathrm{~m}$ ) in a cone shape. The total and useful volumes were $3.0 \mathrm{~L}$ and $2.1 \mathrm{~L}$, respectively. The internal tube $(0.06 \mathrm{~m}$ of diameter) was filled with polyurethane foam cubes $\left(10^{-6} \mathrm{~m}^{3}\right)$ and $30 \%(\mathrm{v} / \mathrm{v})$ of biomass. The internal tube was aerated with an aquarium aerator controlled by a timer. The upflow anoxic reactor had $0.10 \mathrm{~m}$ of diameter, $0.20 \mathrm{~m}$ of height (headspace of $0.10 \mathrm{~m})$. It was filled with cubes $\left(10^{-6} \mathrm{~m}^{3}\right)$ of polyurethane foam cubes and inoculated with $10 \%(\mathrm{v} / \mathrm{v})$ of anaerobic granular sludge. Total and useful volumes were $0.70 \mathrm{~L}$ and $0.45 \mathrm{~L}$, respectively.

\section{Operation conditions}

The study was divided in 8 phases. It started with the anaerobic reactor operating alone, and then the aerobic reactor started in the fourth phase and the anoxic reactor started in the fifth. The Hydraulic Retention Time (HRT) and aeration time changed during the research, due to the great variety of the affluent characteristics and to achieve better conditions.

\section{Wastewater composition}

The influent presented, in average, $3749.43 \mathrm{mg} / \mathrm{L}$ of Chemical Oxygen Demand (COD), $140.87 \mathrm{mg} / \mathrm{L}$ of 
Ammonium Nitrogen $\left(\mathrm{NH}_{4}+-\mathrm{N}\right)$ and $7.65 \mathrm{mg} / \mathrm{L}$ of Total Phosphorous (TP).

\section{Analytical methods}

According to Standard Methods APHA [1] were determined $\mathrm{pH}$, COD, TP, $\mathrm{NH}_{4}+-\mathrm{N}$, Total Kjeldahl Nitrogen (TKN), Total Solids (TS), Total Suspended Solids (TSS) and Volatile Suspended Solids (VSS).

\section{Results and Conclusion}

The results showed that the combined system removed more than $90 \%$ of the organic matter (Figure 1a). The $\mathrm{NH}_{4}+-\mathrm{N}$ concentration reduced from $140.87 \mathrm{mg} / \mathrm{L}$ to $70.18 \mathrm{mg} / \mathrm{L}$ (Figure $1 b)$, but it is not enough to discharge in the water body. In anaerobic conditions, the microorganisms liberate phosphate, which explains the TP increase in anaerobic reactor. In the sequential reactors, the TP concentration decreased (Figure 1c).

Through the results, the combined system composed by anaerobic, aerobic and anoxic reactors can be used to remove organic matter, ammonium nitrogen and total phosphorus from a slaughterhouse wastewater. To have a better efficiency to remove nutrients is necessary to have more studies.

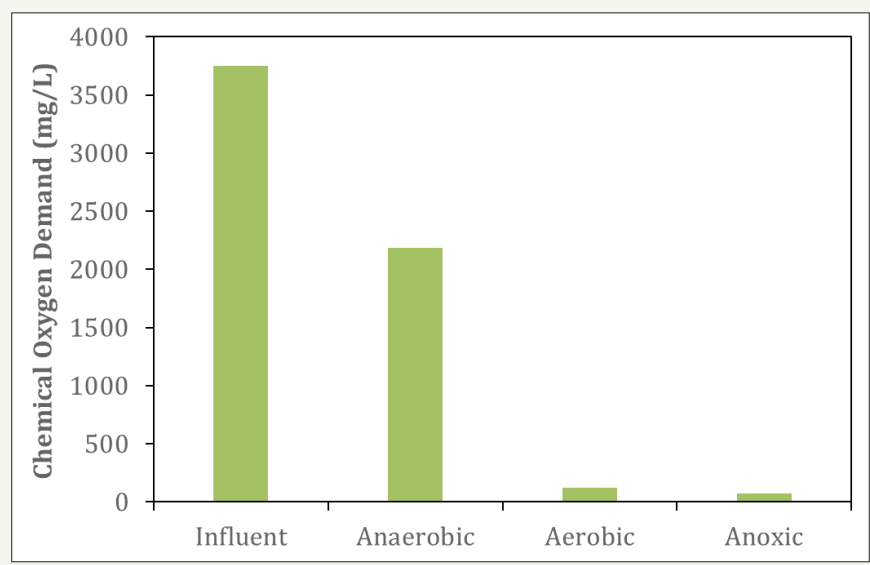

Figure 1a: COD concentrations in the influent and anaerobic, aerobic and anoxic reactors.

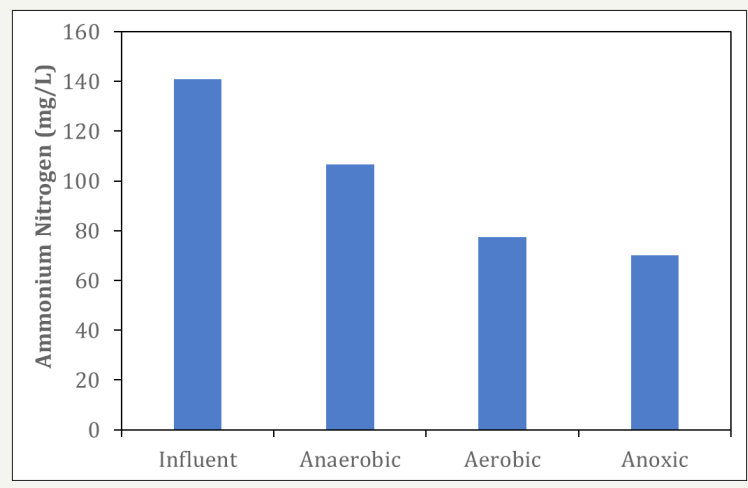

Figure 1b: $\mathrm{NH}_{4}+-\mathrm{N}$ concentrations in the influent and anaerobic, aerobic, anoxic reactors.

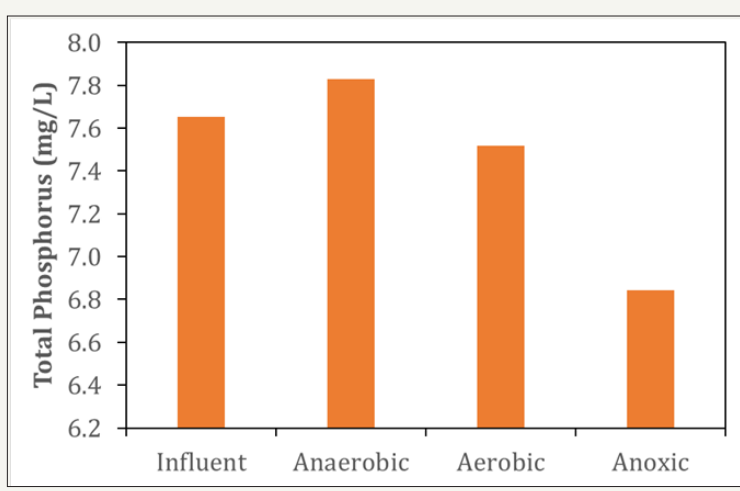

Figure 1c: TP concentrations in the influent and anaerobic, aerobic and anoxic reactors. 


\section{References}

1. APHA (2012) Standard Methods for the Examination of Water and Wastewater. (22 ${ }^{\text {nd }}$ edn.), American Public Health Association, American Water Works Association, Water Environment Federation, Washington, DC, USA.

2. Bustillo-Lecompte CF, Mehrvar M (2015) Slaughterhouse wastewater characteristics, treatment, and management in the meat processing industry: A review on trends and advances. Journal of Environmental Management 161: 287-302.

3. Liu Y, Kang X, Li X, Yuan Y (2015) Performance of aerobic granular sludge in a sequencing batch bioreactor for slaughterhouse wastewater treatment. Bioresource technology 190: 487-491.

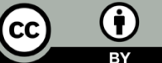

Creative Commons Attribution 4.0 International License

For possible submissions Click Here

\section{Submit Article}

\begin{tabular}{|l} 
Advancements in Civil Engineering \& Technology \\
Benefits of Publishing with us \\
- High-level peer review and editorial services \\
- Freely accessible online immediately upon publication \\
- Authors retain the copyright to their work \\
- Licensing it under a Creative Commons license \\
\end{tabular}

